\title{
REKONTRUKSI SETTING FILM 70-AN PADA IKLAN OVO VERSI "TANGIS TAK BERUJUNG”
}

\author{
Triadi Sya'Dian \\ Prodi Televisi dan Film Universitas Potensi Utama \\ triadisyadian@gmail.com
}

\begin{abstract}
ABSTRAK
Penelitian ini berjudul Rekontruksi setting film 70-an pada Iklan OVO versi "Tangis Tak Berujung". Penelitian ini bertujuan untuk menjelaskan serta memaparkan kreatifitas dan struktur estetik dalam merekontruksi sebuah iklan layaknya film tahun 70-an. Iklan dari OVO menggunakan medium sosial media YouTube dan sempat menjadi trending. Untuk sebuah iklan, iklan ini terbilang sangat berhasil dalam menarik minat khalayak dengan mendapatkan penonton (viewer) sebanyak sembilan juta lebih hanya dalam waktu dua minggu. Penelitian ini bersifat kualitatif menggunakan pendekatan teori estetika kreatifitas dari monroe Beardsley yang menekankan kepada kesatuan, kerumitan, dan kesungguhan. Metode pengumpulan data dengan observasi dan studi pustaka serta wawancara.

Hasil penelitian menunjukkan bahwa iklan OVO versi "Tangis Tak Berujung" mampu dengan sangat baik memvisualisasikan setting film 70-an dan telah memenuhi kaidah estetika pada iklan medium sosial media YouTube.
\end{abstract}

Kata Kunci : rekontruksi, iklan ovo, medium YouTube

\begin{abstract}
This research entitled Reconstruction of the 70s movie setting on the "Tangis tak Berujung" OVO Ad. This study aims to explain and explain the aesthetic creativity and structure in reconstructing an ad like a 70s film. Ads from OVO used YouTube's social media medium and had become trending. For an advertisement, this advertisement is very successful in attracting the interest of the audience by getting more than nine million viewers in just two weeks. This research is qualitative in nature using the aesthetic creativity theory approach from Monroe Beardsley that emphasizes unity, complexity, and seriousness. Methods of collecting data with literature studies, observations, and interviews.

The results of the study show that the OVO advertisement version of "Tangis tak Berujung" was able to very well visualize the setting of the 70s movie and had fulfilled the aesthetic rules of the YouTube social media medium ad.
\end{abstract}

Keywords: reconstruction, ovo's advertising, YouTube medium 


\section{PENDAHULUAN}

\subsection{Latar Belakang}

Iklan adalah bagian dari promosi dimana promosi merupakan bagian dari pemasaran. Menurut R.Kasali (1992), iklan dapat didefinisikan sebagai pesan, dimana pesan tersebut menawarkan suatu produk yang ditujukan kepada masyarakat melalui media yang lebih membujuk orang untuk membeli. Menurut Barban dan Dunn (1996), periklanan merupakan komunikasi non-personal lewat beragam media yang dibayar dengan pesan iklan yang diharapkan dapat menginformasikan dan membujuk kalangan tertentu. Menurut Gilson dan Berkman (1980), Iklan merupakan media komunikasi persuasive yang dirancang guna menghasilkan respond yang membantu tercapainya ojektifitas atau tujuan pemasaran. Sedangkan menurut kamus besar (KBBI), iklan memiliki pengertian pesan atau berita yang bertujuan untuk mendorong, membujuk khalayak ramai agar tertarik pada barang / jasa yang ditawarkan. Oleh sebab itu, visualisasi sebuah kepentingan iklan selalu dibuat semenarik mungkin melalui simbol-simbol tertentu sebagai image atau citra mereknya.

Salah satu iklan yang sangat menarik adalah iklan dari OVO yang diberi judul "Tangis Tak Berujung". OVO adalah aplikasi pintar (smart) bagi pengguna Smartphone yang memberikan kemudahan penggunanya dalam bertransaksi (OVO Cash) (https://www.ovo.id/about). Keunikan dari iklan OVO versi Tangis tak Berujung ialah iklan ini hanya menggunakan medium media sosial Youtube. Banyaknya iklan-iklan yang bermunculan baik di televisi maupun media sosial dengan segala bentuknya, iklan OVO tergolong unik dan lain dari yang lain pada saat ini. Iklan ini menyajikan visualisasi film era 1970-an yang seakan membangkitkan kembali kenangan lama masyarakat jaman tersebut. Hal ini juga tidak menutup kemungkinan menarik ketertarikan minat masyarakat sekarang atau generasi muda yang belum mengetahui bagaimana film di era 1970-an. Fenomena inilah yang menjadi ketertarikan untuk dikaji ketika OVO memberikan iklan warna lama dengan sajian baru pada iklan "Tangis Tak Berujung".

Penelitian ini menggunakan penelitian kualitatif dengan kajian estetika sebagai subjek untuk membaca tampilan iklan. Bahasan menggunakan analisis interpretasi dengan pendekatan estetika. Data yang diperoleh mengenai struktur yang meliputi kesatuan (unity), kerumitan (complexity), dan kesungguhan (intensity) sehingga akhirnya mendapatkan kesimpulan terkait estetika. Semua data mengenai iklan OVO "Tangis tak berujung" berupa audio-visual, wawancara, maupun kepustakaan diklarifikasi sesuai dengan yang dibutuhkan.

\subsection{Teori Kreatifitas Monroe Beardsley}

Estetika berasal dari bahasa Yunani "aisthetika" yang berarti hal-hal yang dapat diserap panca indera. Menurut Dharsono (2007), estetika sering diartikan sebagai persepsi indera. Pengalaman estetik adalah kesadaran terhadap subjek fenomena dan terciptanya ekspektasi kepuasan (Kennick, 1979). Monroe Beardsley (1981), merupakan seorang ahli estetika modern di abad ke-20 memaparkan tentang teori estetika. Dia berpendapat terdapat tiga nilai estetis yang menjadikan baik dan indah.

1. Kesatuan (unity)

Suatu karya seni (estetika) yang tersusun secara baik dalam hal isi, keteraturan dan keserasian dari bentuk, warna, corak, komposisi, dan sebagainya.

2. Kerumitan (complexity) 
Dimana menegaskan bahwa benda estetis bukanlah hal yang sederhana, melainkan kaya akan isi maupun unsur-unsur yang saling berlawanan ataupun mengandung perbedaan-perbedaan yang halus.

3. Kesungguhan (intensity)

Sesuatu yang memiliki kualitas tertentu yang menonjol dan bukan sebagai karya kosong, seperti gembira atau suram, sifat kasar atau lembut, serta merupakan sesuatu yang intensif dan sungguh mampu mengekpresikan suatu emosi.

\section{STUDI LITERATUR}

Beberapa referensi penulisan pustaka yang dirujuk dalam tulisan ini adalah sebagai berikut :

Penelitian dari Decky Avrilukito Ismandoyo yang berjudul "Estetika Iklan Televisi Axe Versi "Kencan Dengan Bidadari". Penelitian ini menjelaskan serta memaparkan struktur estetika dari sebuah iklan. Langkah proses dalam mencapai tujuan ilmiah dengan pendekatan fenomena sebuah iklan yang telah ada. Penelitian terfokus pada iklan televisi Axe Indonesia versi "Kencan Dengan Bidadari". Data kualitatif dikumpulkan dengan cara pengamatan serta analisis dokumen dari gejala - gejala mendalam yang terekam dan menganalisa secara deskriptif analitik. Penelitian ini mendeskripsikan secara runtun sesuai proses alur berpikir. Dalam proses pengerjaan penelitian menggunakan teori estetika iklan dan medium televisi.

Karena iklan Axe mendapat teguran dari Komisi Penyiaran Televisi (KPI) maka dibuatlah iklan Axe pengganti agar tampil lebih baik. Dengan tampilnya iklan Axe pengganti maka visualisasinya dibuat tetap semenarik mungkin namun lebih berhati-hati. Menariknya iklan Axe pengganti di sini dalam konteks penyajian estetikanya tidak dapat terlepas dari unsur wanita dan kesan sensual yang ditampilkan sebagai ciri khas iklannya tersebut. Unsur wanita dan kesan sensual tetap sama namun penyajian iklannya yang berbeda. Penyajian iklan Axe pengganti ini ternyata sangat menarik perhatian sehingga membuat khalayak sasaran selalu menjadikannya buah bibir.

Hasil penelitian berupa analisa tentang estetika iklan Axe pada medium televisi yang disimpulkan menjadi tiga inti pokok. Pertama, mengenai pembentuk estetika. Iklan Axe versi Indonesia "Kencan dengan Bidadari" telah memenuhi tiga unsur yang membuat baik (indah) secara estetika Beardsley yaitu kesatuan (unity), kerumitan (complexity), dan kesungguhan (intensity). Kedua, mengenai Produk Axe yang telah melakukan kegiatan penyampaian pesan ke sasaran khalayaknya melalui medium televisi yang tayang tahun 2012. Pesan yang telah disampaikan merek adalah dengan menggunakan produk Axe maka akan mendapatkan simpati dari para wanita cantik yang ditemuinya. Bahkan wanita cantik yang tertarik adalah bidadari yang seolah mengajak kencan hingga turun ke bumi. Ketiga, mengenai elemen pembentuk iklan. Pada iklan televisi Axe telah tersajikan elemen pembentuk audio dan visual. Ini membuktikan bahwa medium televisi cukup exposure dari kelebihan dan kelengkapan yang disajikan oleh elemen pembentuknya.

Penelitian berjudul Mini Drama "Ada apa dengan Cinta 2014" versi iklan line Indonesia oleh Mirza Febrianti. Pembahasan dalam penelitian ini adalah mengenai sajian mini drama "Ada Apa dengan Cinta 2014" dari sudut pengambilan gambar serta sajian promosi melalui sosial media. Penelitian ini bertujuan untuk mengetahui arti atau makna sebuah pengambilan gambar dari masing-masing tokoh dalam mini drama "Ada Apa Dengan Cinta 2014", serta untuk 
mengetahui teknik promosi fitur "Find Alumni" yang terdapat pada aplikasi LINE yang disebarkan melalui sosial media kepada khalayak. Metode penelitian yang digunakan adalah kualitatif interaktif, dimana sebuah penelitian ditandai dengan adanya interaksi antara seorang peneliti dengan yang diteliti. Data penelitian di olah dan dikaji menggunakan tiga aspek teori, yaitu aspek unity, aspek complexity, dan aspek intensity milik Monroe Breadsley.

Hasil penelitian dapat disimpulkan bahwa, film yang diteliti merupakan sebuah film berdurasi pendek dan bergenre drama. Film "AADC 2014" pada iklan LINE layak disebut sebagai mini drama karena memiliki dua kriteria yaitu, berdurasi kurang dari 15 menit dan bergenre drama romantis. Terdapat beberapa faktor yang mendukung terciptanya sebuah mini drama yaitu, tokoh pemeran, alur cerita, audio visual, penataan lampu, serta melalui tahap pra produksi hingga pasca produksi. Mini drama "AADC 2014" yang diproduksi oleh LINE memiliki ciri khas yang dapat menarik minat penonton yaitu, menggunakan aktor dan aktris yang sama pada film "AADC" tahun 2002, dan bukan sekuel kedua dari film "AADC". Pemeran "AADC 2014" tidak lagi menjadi siswa dan siswi SMA, melainkan sudah beranjak dewasa.

Mini drama "AADC 2014" dianalisis menggunakan teori Monroe Breadsley. Teori Monroe Breadsley memiliki tiga aspek yaitu, aspek Unity, aspek Complexity, dan yang terakhir adalah aspek Intensity. Karakter masing-masing tokoh mini drama menjadi temuan peneliti yang mewakili aspek Complexity, hasil analisis pada tokoh utama dapat disimpulkan bahwa Cinta merupakan seseorang yang memiliki karakter peragu dan pemikir. Aspek kedua yaitu Unity, secara menonjol dapat dilihat dari sinematografi pada adegan masing-masing tokoh secara detail, terlihat dari analisis adegan Rangga ketika diambil dari sudut low angle yang menggambarkan sikap optimis dan percaya diri. Aspek Intensity dapat ditemukan dari konsistensi sajian visual gambar dengan alur cerita, seperti pengambilan gambar ketika Cinta berada di sebuah kafe, lokasi kafe merupakan pemilihan lokasi yang tepat dengan alur cerita karena, kafe merupakan tempat yang nyaman untuk melepas penat dan berkumpul dengan kerabat terdekat.

\section{PEMBAHASAN}

A. Estetika Kreatifitas

Iklan OVO versi "Tangis Tak Berujung" manampilkan setting di areal taman dengan frame ratio 4:3 menciptakan kesan sebuah film tahun 1970-an. Dengan settingan Sound yang sedikit noise menciptakan ciri khas karakter video film tempo dulu. Terdapat dua pemeran pria yang bernama Oma dan wanita bernama Ani yang sedang berdialog dibarengi dengan backsound. Terlihat gesture dan mimik keduanya sedang dalam suasana tegang akibat konflik. Gerakan sang pria memutari wanita dengan gesture tangan terangkat sambil berdialog disertakan mimik wajah serius menggunakan nada tinggi. Sang wanita dengan gesture tangan menutup telinga disertakan mimik wajah histeris sambil menjerit. Saat itu sang pria mempermasalahkan pembayaran taksi online. Kemudian dijawab oleh wanita tentang bagaimana cara pembayaran taksi tersebut hanya menggunakan aplikasi. Scene ini berakhir dengan tibanya seseorang dibelakang mereka yang diisyaratkan sebagai supir taksi online tersebut. Puncak dari iklan ini diakhiri dengan adanya adegan konflik mengenai pembayaran kembali dengan latar belakang di sebuah restaurant. Konflik terakhir seolah menekankan bahwa OVO merupakan sebuah aplikasi yang mampu menangani semua pembayaran. Berikut adalah ilustrasi iklan OVO yang disajikan frame by frame yang terlihat pada tabel 1. 
Tabel 1. Iklan OVO "Tangis tak Berujung"

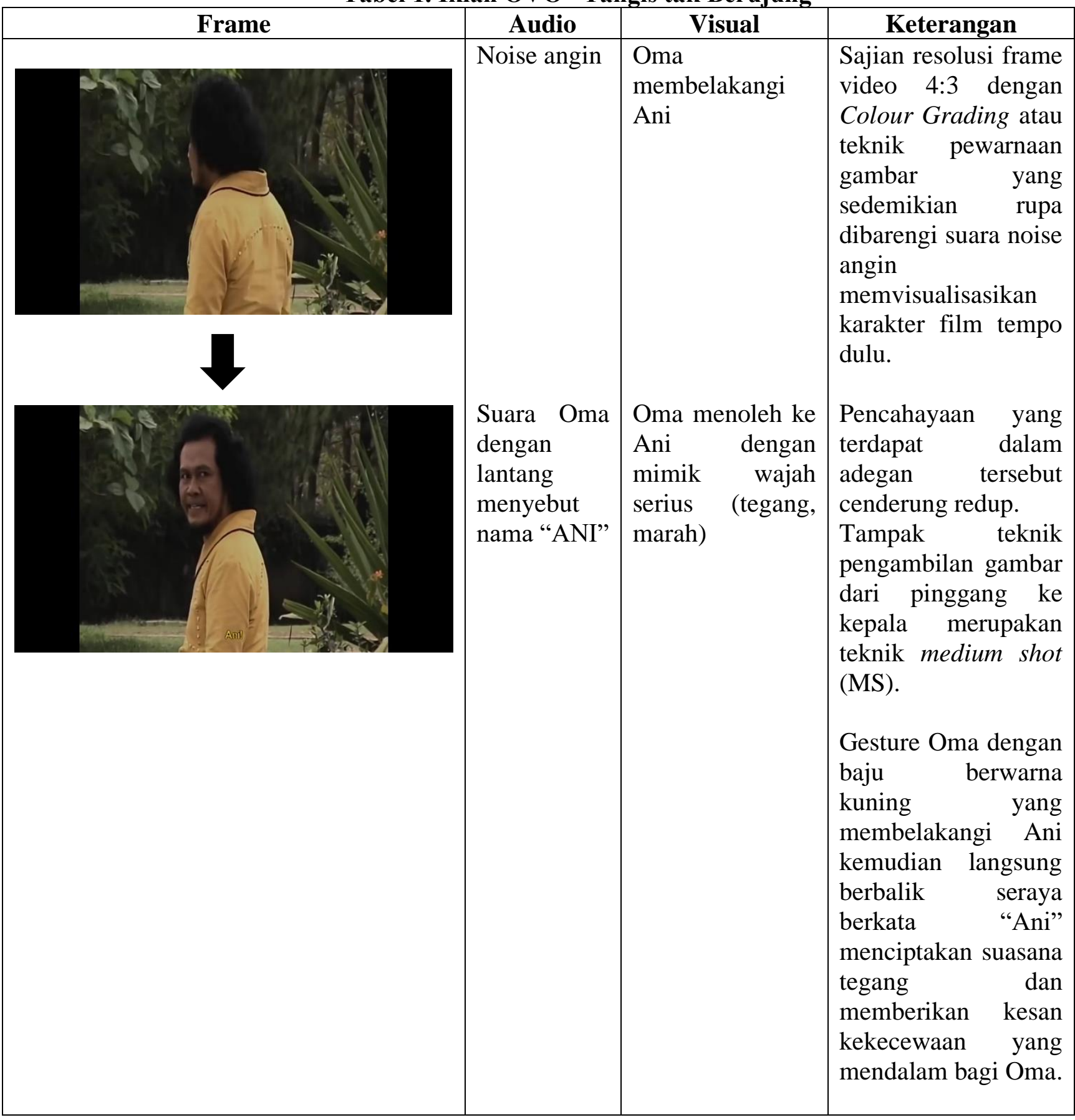




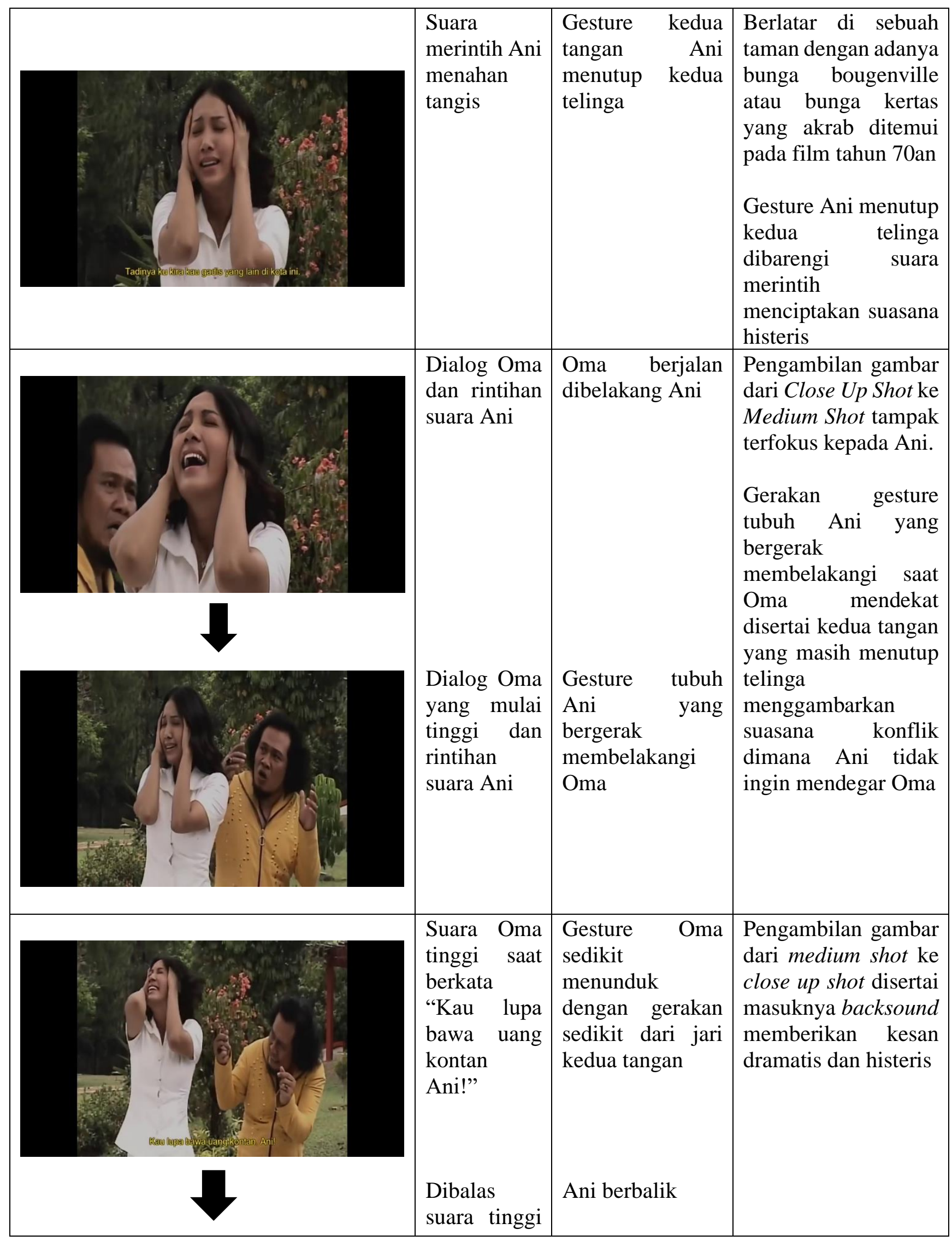




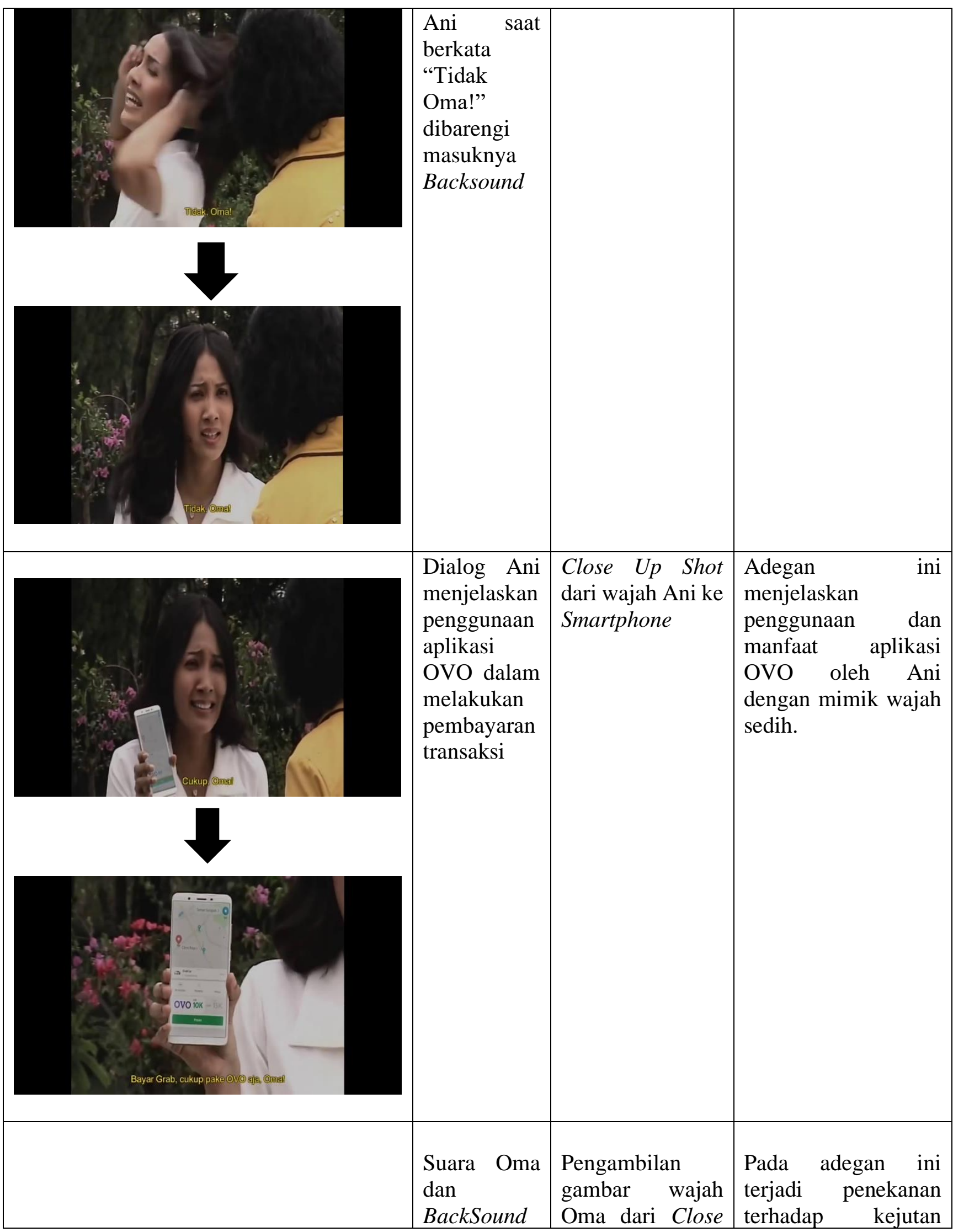




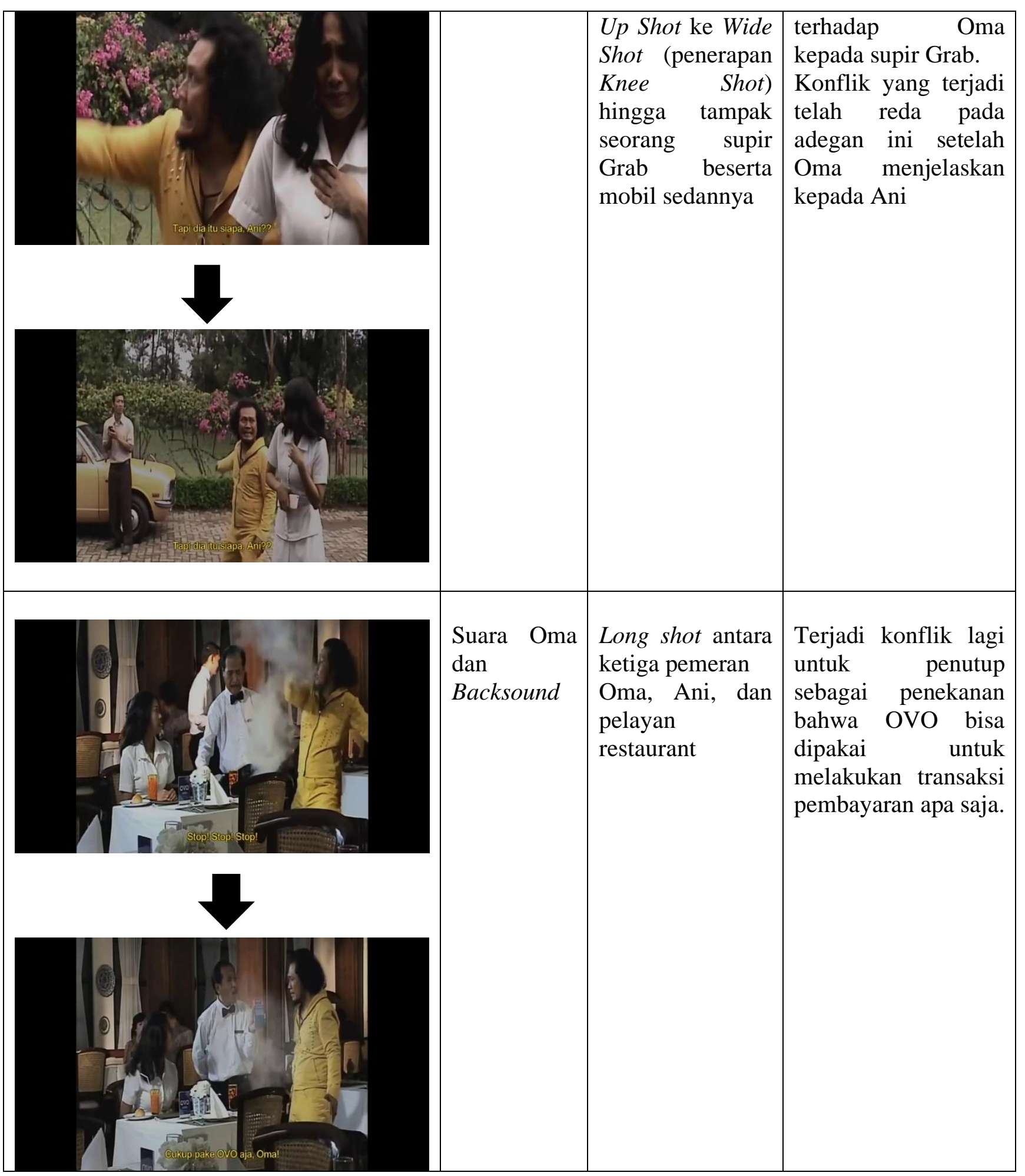

(Sumber : Youtube.com / Scene Cut video : Triadi, 2018)

Tiga unsur yang membuat baik (indah) secara estetika dari iklan OVO versi "Tangis Tak Berujung" dari Beardsley adalah : 
1. Kesatuan (unity)

Dalam kesatuan warna (color grading) cenderung redup. Penyajian gambar dengan rasio resolusi 4:3 yang disertai warna redup tersebut sesuai dengan visualisasi karakter film yang ada pada era 70-an. Pemilihan busana pria yang berwarna kuning yang sengaja dibuat kontras menciptakan representasi busana lawas. Berlatar belakang disebuah taman yang dipenuhi bermacam bunga bougenville dan sebuah mobil sedan klasik tampak pada adegan penutup konflik pertama. Semua objek penyusun yang ada pada iklan OVO berhasil menyatukan sebuah keseimbangan kesatuan dalam visualisasi iklannya.

2. Kerumitan (complexity)

Visualisasi yang disajikan memiliki kaya akan makna melalui potensi unsur yang saling berlawanan dari menyatukan yang lawas dengan sesuatu hal yang baru. Seperti sebuah smarthphone yang ditampilkan berdampingan dengan sebuah sedan klasik. Visualisasi yang kontras menjadi keunikan tersendiri pada iklan ini.

3. Kesungguhan (intensity)

Secara keseluruhan iklan dibangun dengan kualitas yang sangat unik dan kreatif. Kesungghuan kualitas dapat dilihat dan dirasakan dari bagaimana perwatakan kedua pemeran yaitu Oma dan Ani yang mampu menghadirkan visualisasi histeris seperti film era 70an.

\section{B. Iklan Medium Youtube}

Seperti yang telah dikatakan pada teori bahwa iklan merupakan penyampaian pesan ke sasaran khalayak (Wells, dkk, 2007). Iklan OVO bersi "Tangis tak Berujung" telah melakukan kegiatan penyampaian pesan kepada khalayak melalui medium sosial media Youtube. Youtube merupakan situs website berbagi video. Youtub memberikan fitur monetize, yaitu memberikan kesempatan kepada pembuat video (content creator) yang memiliki penonton (viewer) yang banyak untuk mendapatkan sebuah tayangan adsense atau iklan disela videonya. Tayangan iklan ini akan memberikan keuntungan bagi pemilik video jika penonton mau melihat iklan lebih lama pada videonya.

Pembuat (creator) iklan OVO memilih ranah sosial media sebagai target penyampaian pesan iklannya. Dan strategi OVO bisa dikatakan berhasil, terbukti selang dua minggu sejak tanggal 28 November 2018 iklan ini ditayangkan di Youtube, sudah mencapai sembilan juta viewer lebih. Para penonton dengan sengaja mencari dan menonton iklan tersebut hingga selesai.

\#PakeOVOAja

Tangis Tak Berujung

$9,730,339$ views

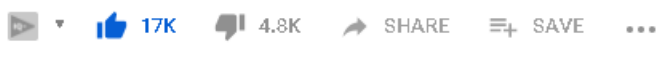

Daripada drama berkepanjangan seperti dua insan ini, bayar Grab, Tokopedia, tagihan, sampai belanja di lebih dari 100.000 outlet Cukup \#PakeOVOAja!

Gambar 1. Konten iklan "Tangis tak Berujung" di Youtube milik OVO 
Tampak dari gambar diatas bahwa iklan tersebut mampu menarik perhatian khalayak ramai khususnya para pengguna gadget yang suka menonton di Youtube. Berikut komentar dari beberapa penonton Youtube terhadap iklan OVO versi "Tangis tak Berujung" :

\begin{tabular}{|c|c|}
\hline $\begin{array}{c}\text { Penonton } \\
\text { (viewer) }\end{array}$ & Komentar \\
\hline $\begin{array}{l}\text { Kood Design } \\
\text { Art }\end{array}$ & $\begin{array}{l}\text { Kood Design Art } 1 \text { week aga 2,837 subscribers } \\
\text { Harus TRENDING NIH iklan yang kreatif kyak gini, bikin ngakak } \\
\text { Like yang ngakak } \\
\text { \० }\end{array}$ \\
\hline Rosso Nerry & $\begin{array}{l}\text { Rosso Nerry } 1 \text { week ago } 0 \text { subscribers } \\
\text { selamat datang di indonesia dimana iklan lebih menarik ktimbang acara TV nya } \\
\text { I } 249 \text { REPLY } \\
\text { View } 14 \text { replies } \checkmark\end{array}$ \\
\hline $\begin{array}{l}\text { Deddy } \\
\text { Headbangers }\end{array}$ & $\begin{array}{l}\text { Dedy Headbangers } 2 \text { weeks ago } 4,877 \text { subscribers } \\
\text { wkwkwkwkwk yang langsung OTW ke channel ini gara2 liat iklan. } \\
935 \quad \text { REPLY } \\
\text { View } 40 \text { replies } \vee\end{array}$ \\
\hline Hardi Mahessa & 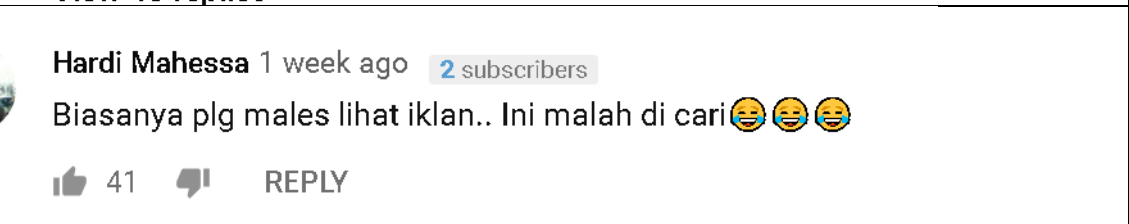 \\
\hline Blitz Autopro & $\begin{array}{l}\text { blitz autopro } 1 \text { week ago } \\
\text { I luv } 90 \text { s comercial }\end{array}$ \\
\hline Pras Gati & $\begin{array}{l}\text { Pras Gati } 1 \text { week ago } 0 \text { subscribers } \\
\text { Seumur umur liat youtube,baru kali ini nge like iklan. ITU SEMUA GARA2 KAMU ANI.....maaf ak } \\
\text { khilaf. Hahahaha... }\end{array}$ \\
\hline Cepi Cahyana & $\begin{array}{l}\text { cepi cahyana } 2 \text { weeks ago } 25 \text { subscribers } \\
\text { biasanya aku skip klw ada iklan, ini aku malah nyari chanel nya :D } \\
244 \quad \text { REPLY }\end{array}$ \\
\hline
\end{tabular}

\section{KESIMPULAN}

Analisa tentang Rekontruksi setting film 70-an pada iklan OVO versi "Tangis tak Berujung" pada medium social media Youtube, maka dapat disimpulkan : 
1. Iklan OVO versi "Tangis tak Berujung" mampu memvisualisasikan setting film 70-an dimana telah memenuhi tiga unsur yang membuat (indah) secara estetika Beardsley yaitu kesatuan (unity), kerumitan (complexity), dan kesungguhan (intensity).

2. OVO menggunakan medium sosial media YouTube sebagai penyampaian pesan kepada khalayak ramai. Sebuah strategi penyampaian yang ditujukan hanya kepada pengguna gadget (smartphone). Hanya dalam waktu dua minggu, iklan OVO berhasil meraih sembilan juta lebih penonton, dan untuk sebuah iklan, strategi ini terbilang berhasil dengan banyaknya respon positif dari kalangan pengguna gadget.

3. Penyajian elemen pembentuk audio dan visual pada iklan OVO versi "Tangis tak Berujung" pada medium YouTube telah tersaji dengan sangat baik. Penyajian visualisasi objek yang kontras menjadi daya tarik keunikan tersendiri yang mampu menarik perhatian khalayak.

\section{DAFTAR PUSTAKA}

[1] Dunn, S. Watson \& Arnold M. Barban (1986). Advertising: ots Role in Modern Marketing. ( $6^{\text {th }}$ Ed). Chicago: The Dryden Press

[2] Gilson, Christopher \& Harold W.Berkman (1980), Advertising: Concepts and Strategies, New York:Random House Inc.

[3] https://www.youtube.com/watch? $v=f N w U Q z x Q d U A$

[4] Kasali, Rhenald. (1992). Manajemen Periklanan Konsep dan aplikasinya Di Indonesia. Jakarta: Pustaka Utama Grafiti

[5] Monroe, Beardsley (1981), Problems in the Philosophy of Criticism, 2nd Ed, Hackett Publishing Company Inc.

[6] Wells, W., dan Sandra Moriarty, John Burnet, May Lwin (2007), Advertising: Principles and Effective IMC Practice, Prentice Hall. 